\title{
A Systematic Review on Usability Evaluation for University Websites
}

\author{
Adedeji F.M \\ Babcock University \\ Ilishan-Remo, \\ Nigeria
}

\author{
Adekunle Y.A \\ Babcock University \\ Ilishan-Remo, \\ Nigeria
}

\author{
Adebayo A.O \\ Babcock University \\ Ilishan-Remo, \\ Nigeria
}

\author{
Alao O.D \\ Babcock University \\ Ilishan-Remo, \\ Nigeria
}

\author{
Akande $\mathrm{O}$ \\ Babcock University \\ Ilishan-Remo, \\ Nigeria
}

\begin{abstract}
Usability of websites has been studied severally in a general term in different sectors such as entertainment, social media and e-commerce. Higher education is a sector that needs more attention because Universities are very important in the society and their websites hold important information for prospective students, parents, faculty, students of the university and the public. Several literature reviews have been conducted on website usability evaluation, not many have focused on University website usability evaluation. Existing reviews of University website usability evaluation have based their review on certain aspect of usability evaluation such as the methods used. The objective of this study is to carry out a systematic literature review of recent studies in this area in order to provide insight for University website developer, usability researchers and higher academic institutions in all. This study focuses on researches conducted on University website usability evaluation from 2016 to 2021. Findings from this study include additional information different from existing literature review, such as, objectives of researches, common usability attributes used by usability researchers, methods of data collection and analysis, changes in data collection due to Covid-19 pandemic and the types of usability problems found. The commonly mentioned usability problems are problems related to interface design, content, navigation, performance and accessibility.
\end{abstract}

Keywords: University website, usability evaluation, user experience, human computer interaction

\section{INTRODUCTION}

The Internet has evolved rapidly and turned into a medium for worldwide communication. Website is part of the Internet that provides the ability for individuals and organizations to share information with their users and it has become inevitable for businesses that want to stay competitive in the Covid-19 era. Having a website has become vital for Universities [1] as it is an interface to provide information to students, faculty, prospective students, alumni, parents and the public. Information such as, admission criteria for prospective students, courses offered, news updates, fees etcetera are displayed on the websites [2]. All these users visit the University website for various purposes and they differ in terms of their frequency of use and competence with the use of technology [3]. Their expectations vary, therefore the University website should be designed to cater for these variations. For Universities to provide needed information and carry out their transactions there is the need for functional and usable website [4].

Usability is defined as "the extent to which a system, product, or service can be used by specified users to achieve specified goals with effectiveness, efficiency, and satisfaction in a specified context of use" [5]. Usability is an important feature for a website to have [6]. If a website is found not usable or not meeting users' needs, they leave for other websites, those who manage to stay lead to frequent customer inquiries, support and subsequently lead to loss of revenue for website owners. Evaluating the usability of websites is helpful for locating problems with the interface design or its usage.

Usability of University websites has been studied by several researchers who have applied various methods to evaluate University website's usability. This gives information to the website developer on areas that need improvement. In this study, we carry out a systematic review of usability evaluation of University websites from the past 6 years, to gather information about trends, methods, and other information that are beneficial to University website developers, researchers and usability experts.

Several literature reviews have been conducted on website usability evaluation, not many have focused on University website usability evaluation. Literature reviews on University website evaluation have based their review on certain aspect of usability evaluation such as the methods used. [7] Performed a systematic literature review to find the trends in accessibility of University websites published in 42 papers. The result presented analysis of evaluation of 9140 Universities in 67 countries. The report presented important accessibility problems. A survey on research trends on University website usability was conducted by [4]. A total of 35 scholarly articles were reviewed. The review was based on usability evaluation methods, MCDM approaches and automated tools. The result revealed that the most common methods of usability evaluation are heuristics evaluation, user testing and automated tools. MCDM approaches are 
increasing but not as much as other methods. [8] In their study evaluated University website usability evaluation from scholarly articles from 2006 to 2016. 53 papers were investigated and the result showed that the generally adopted method are user testing and questionnaire, the most reported usability issues were navigation, UI design and information content quality. This study reviewed more recent studies from 2016 to 2020, in addition to the methods of usability evaluation on University website we highlight other aspects like metrics used, objectives of study etcetera. This is to provide adequate information for Universities web developers and usability researchers. The rest of the paper is structured as follows: section 2 presents the method applied, section 3 presents the analysis of the result and lastly section 4 the conclusion from the analysis is discussed.

\section{METHOD}

A systematic review involves a process to systematically search and locate relevant studies about a research question and systematic presentation of the finding of the result from the search [9]. In this study, a systematic review was adopted because it involves a comprehensive search to locate relevant literature about a given concept. It tends to be of higher quality, transparent, more comprehensive and less biased than other literature review approaches. The Preferred Reporting Items for Systematic Reviews and Meta-Analyses (PRISMA) reporting standard was adopted in this study because it is most widely applicable across different research areas. PRISMA was developed by [10] and is made up of four stages namely: identification, screening, eligibility and inclusion as shown in Figure 1. To achieve the main purpose of this study which is to gather information about trends and methods that have been adopted in conducting usability evaluation of university websites, the following research questions were determined:

1. In which countries were these studies carried out?

2. What is the distribution of studies by year?

3. What are the objectives of carrying out the studies?

4. What are the usability metrics considered in the studies?

5. What are the methods of website usability evaluation adopted?

6. How and what type of data is collected?

7. What data analysis method was used?

8. What is the stage of evaluation?

9. Which web pages were selected for evaluation?

10. What type of problems were found?

11. What measures were taken considering Covid-19 pandemic?

The identification stage involved the process of identifying relevant literature from electronic databases. In acquiring the relevant information, Google Scholar and IEEE were accessed. Search parameters such as "Evaluation of Academic website", "Usability of academic websites", Usability of higher education websites", "University website evaluation" were used to search for articles. This study focused on more recent articles published between 2016 and 2021. Usability evaluation for visually impaired, mobile interfaces were excluded because the focus of the study is mainly on websites, further study will focus on usability for visually impaired. The inclusion and exclusion criteria considered are highlighted in table 1 . Titles that included usability, quality, accessibility, navigation were included because these are usability metrics that have to do with usability evaluation. After identification, 84 articles were selected. In the screening stage, the search result was screened, a quick scan of the abstract was done and articles that had potentials of relevance selected, duplicate articles were removed. In the eligibility stage, the full texts of the articles were studied, focusing on their relevance as regards the research questions formulated. At this stage, different metrics, elements and methods used by researchers were identified and these articles were chosen at the inclusion stage. At the end 32 articles were selected, 2 could not be downloaded.

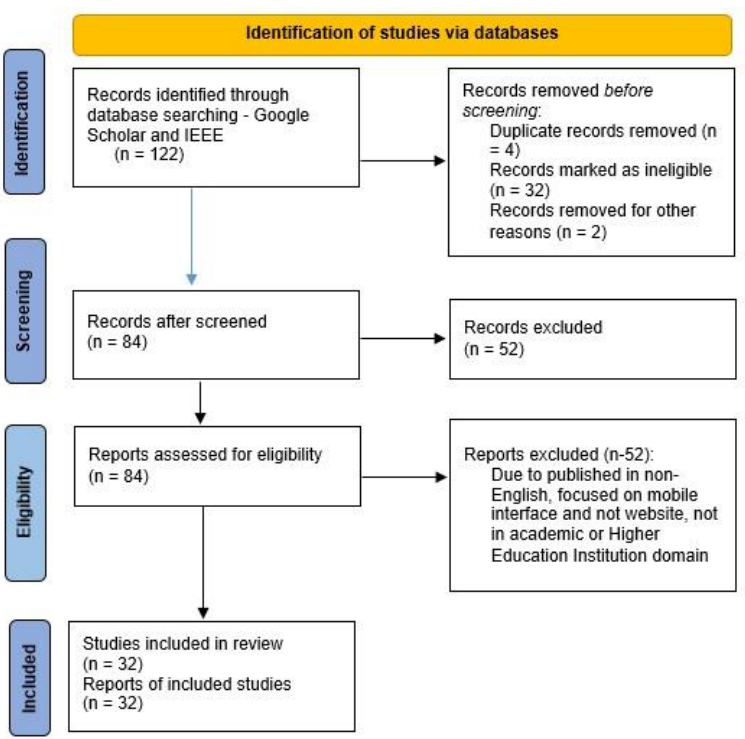

Figure 1 Data abstraction based on PRISMA flow diagram (Moher, 2013)

Table 1 Criterion for Screening

\begin{tabular}{|l|l|l|}
\hline Criteria & Inclusion & Exclusion \\
\hline Language & English & Non-English \\
\hline Interface & Website & $\begin{array}{l}\text { Mobile interface } \\
\text { and others }\end{array}$ \\
\hline Type of study & $\begin{array}{l}\text { Usability and its } \\
\text { elements }\end{array}$ & $\begin{array}{l}\text { Not focused on } \\
\text { usability }\end{array}$ \\
\hline Publication date & $2016-2021$ & Before 2016 \\
\hline
\end{tabular}




\section{FINDINGS}

In this section the findings of the systematic literature review based on answers to the research question are summarized, a total of 32 articles were selected and analyzed.

\subsection{In which Countries were these Studies carried out?}

In this study, 17 countries contributed to the review. The countries with the highest contribution are shown in figure 3.2 Jordan and Indonesia had the highest with 4 articles each, followed by Pakistan and Turkey with 3 articles each. However, in a comparative study carried out by [11], 348 Universities in Latin America were evaluated. This was not included in the countries in figure. 3.1

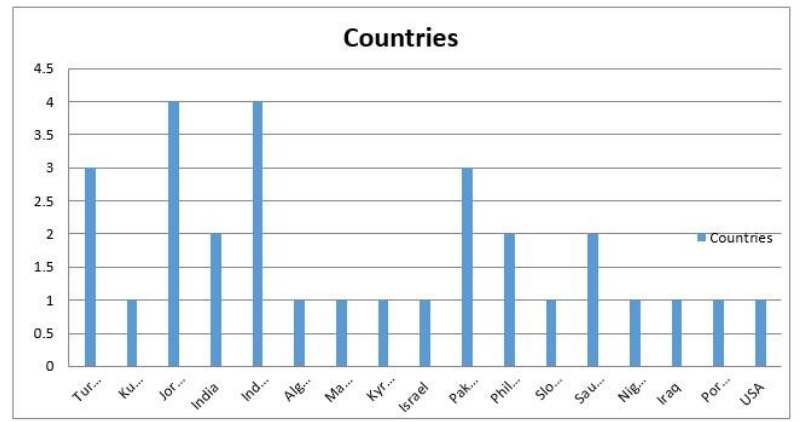

Figure 3.1 Distribution of articles by country

\subsection{What is the Distribution of the Studies}

\section{by Year?}

More recent researches were considered in this study, the articles considered are articles from 2016 to 2021. This is due to the fact that there is a similar study by [8] of articles from 2006 to 2016 . The distribution of the studies by year can be seen in figure 3.2. The year with the highest number of articles is 2019 with 8 articles, 2020, 2018 and 2016 had the same number of articles each which is 6.2021 had the least number of articles.

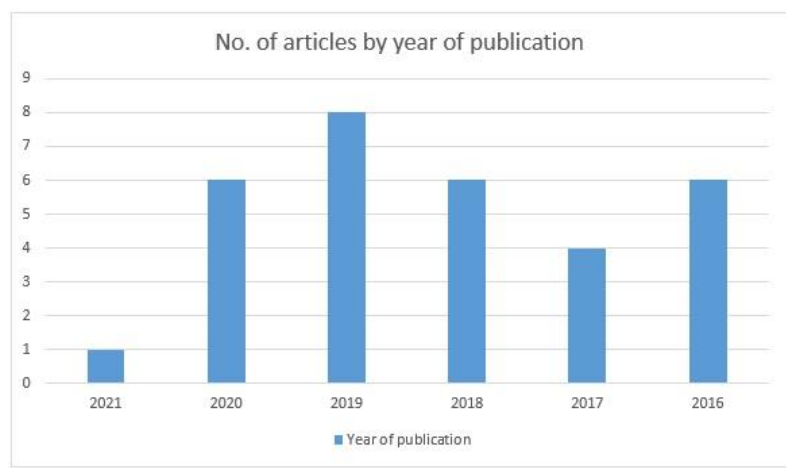

Figure 3.2 Distribution of articles by year

\subsection{What are the Specific Objectives for carrying out the Studies?}

In all the articles studied, researchers have specific objective for carrying out usability studies. These objectives were investigated and categorized into 7 as shown in Figure 3.3. $41 \%$ of the articles had the objective of evaluating the usability of the University website using different metrics and methods, $28 \%$ were interested in the accessibility of the University website, $16 \%$ were interested in determining the variables that affected users of the website, $6 \%$ investigated the navigability of the website and $3 \%$ were interested in assessing the performance, $3 \%$ proposed a model for University website evaluation, $3 \%$ compared the performance of automated tools on websites.

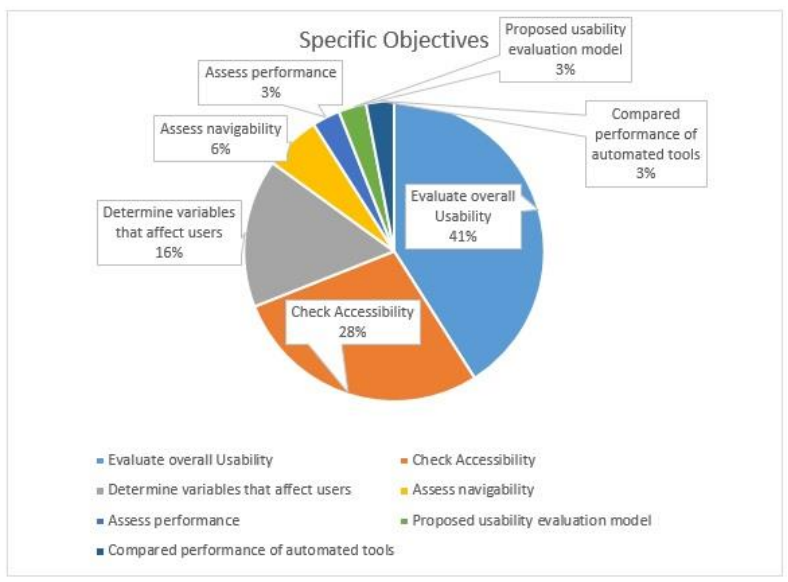

Figure3.3 Specific Objectives for University website evaluation

\subsection{What are the Usability Metrics considered in the Studies?}

Definition of metrics is an important aspect of any usability evaluation. This is what guides the data collection process. Several metrics were employed in the articles investigated; these metrics are measured by different criteria [12]. Some studies used standard usability metrics such as effectiveness and efficiency, while some studies devised metrics according to the intention of their study. Figure 3.4 shows the standard metrics employed, with accessibility being the most used, followed by usability. Other metrics such as load time, number of pages, interface design were also used. 


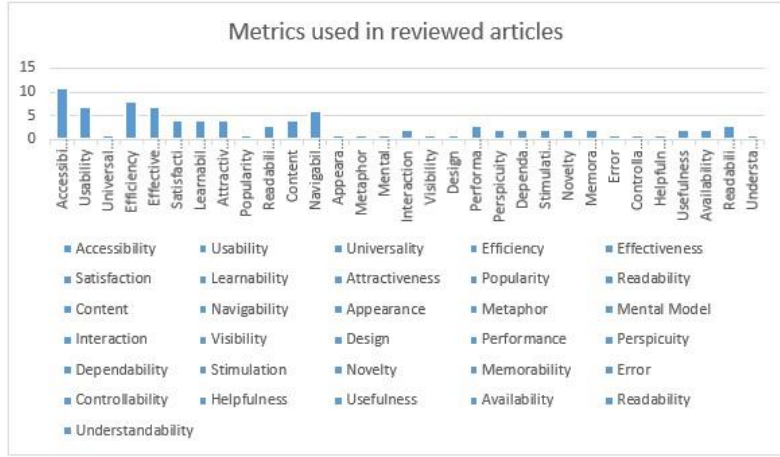

Figure 3.4 Metrics employed in studies

\subsection{What are the Methods of Website Usability Evaluation adopted?}

The methods of evaluation used in this study are basically classified into three: the inspection method, empirical method and tool based method. The inspection method involved usability experts checking the website interface to identify usability problems by checking it against standard usability checklist or guidelines usually referred to as heuristics [13]. The Empirical method involves real users accessing the website to identify usability problems with the website; usage data is collected with data collection methods such as questionnaires and there after analyzed. Some of the studies employed online tools and automated tools that check website usability against standard checklist and guidelines such as the Web Content Accessibility Guidelines (WCAG), Search Engine Optimization (SEO), and site security etcetera. As shown in Figure 3.5, 47\% of the university website evaluation studies were conducted with automated tools $31 \%$ as empirical method, followed by $9.4 \%$ for inspection method. There were instances where the experts inspected website manually in conjunction with automated tool [14] or manual inspection with empirical method [15] and empirical method was used in conjunction with automated tool [16]. Frequent techniques used under empirical methods are questionnaires and survey, user interaction log was used by two studies [17] [18].

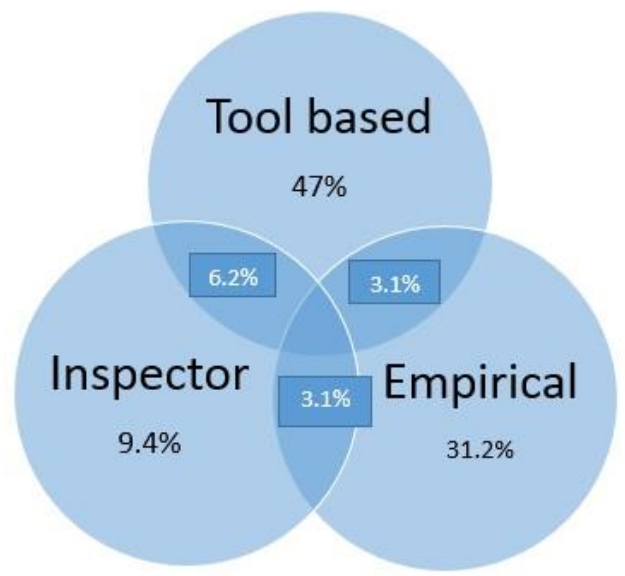

Figure 3.5 University website Usability evaluation methods

\subsection{How and what type of Data was collected?}

Mostly quantitative method was used for data collection, basically with questionnaires and survey, qualitative method such as interview, observation, think aloud and focus groups also adopted as show in Figure 3.6. Two studies collected website user interaction data by embedding JavaScript code into web pages of the website [17] [18]. Interaction such as mouse clicks, scrolls and cursor movement were captured and analyzed to identify usability problems.

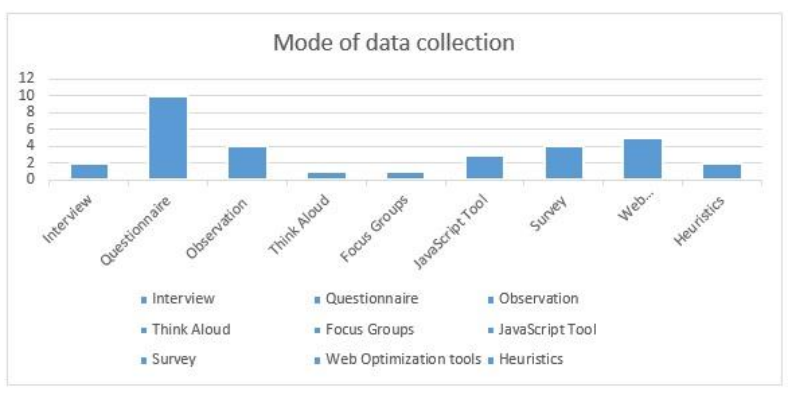

Figure 3.6 Mode of data collection

\subsection{What Data Analysis Method was used?}

The data analysis method used in the study was mostly descriptive analysis with $87.5 \%$ of the studies and predictive analysis was $12.5 \%$ as shown in Figure 3.7. The descriptive analysis results were reported using percentages, mean, median and mode. One study rendered user interaction in heat maps [18]. Some others applied predictive analysis such as Krug's test, linear programming, linear regression, AHP and correlation [19] [3] [20].

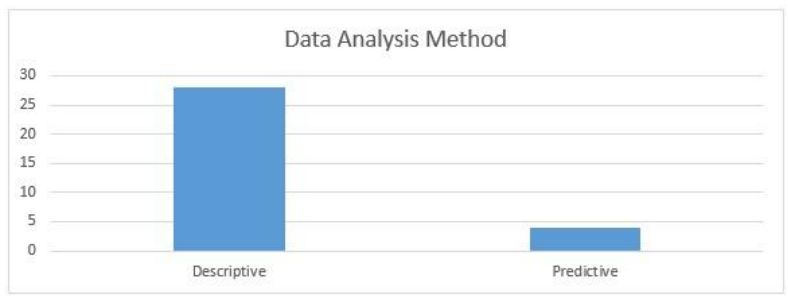

Figure3.7 Method of data analysis

\subsection{What is the Stage of Evaluation?}

All but one of the studies went through the formative form. Evaluation was done on University websites that were already existing and completed. One study carried out evaluation at the pre-production stage [18].

\subsection{What Types of Web Pages were Evaluated?}

The types of pages web pages that were evaluated in the studies were investigated. Not all the studies specified the web pages evaluated. The investigation shows that the homepage was evaluated more than other pages as shown in Figure 3.9. 


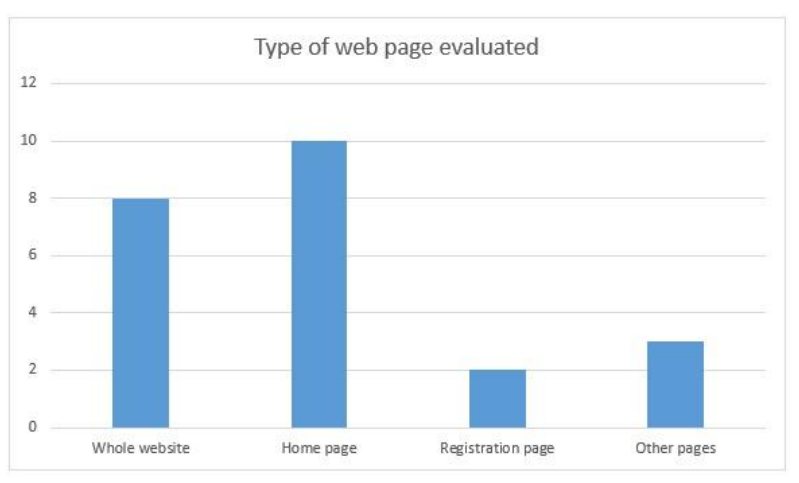

Figure 3.9 Types of web page evaluated

\subsection{What are the Usability Problems Found?}

The usability problems found in the studies reviewed are categorized into 5 as shown in Table 2. The most common usability issues are interface design related issues, navigation, content, performance and accessibility issues.

Table 2 Usability problems found

\begin{tabular}{|c|c|}
\hline Usability Problems & \\
\hline Interface design & $\begin{array}{ll}\text { - } & \text { Missing Alternate text } \\
\text { - } & \text { Errors in code (e.g. } \\
\text { html errors) } \\
\text { - } \\
\text { - } \text { Eesign outdated } \\
\text { - } \quad \text { Not mobile friendly } \\
\text { - } \quad \text { Lack of icon } \\
\text { description } \\
\text { - Search box too small }\end{array}$ \\
\hline Navigation & $\begin{array}{ll}\text { - } & \text { Broken links } \\
\text { - } & \text { Page not found } \\
\text { - } & \text { Inappropriate labelling }\end{array}$ \\
\hline Content & $\begin{array}{ll}\text { - } & \text { Instant feedback } \\
\text { missing } \\
\text { - } & \text { FAQ not available } \\
\text { - } & \text { Missing information } \\
\text { - } & \text { Search returning empty } \\
\text { information }\end{array}$ \\
\hline Performance & $\begin{array}{ll}- & \text { Slow loading time } \\
\text { - } & \text { Lack of security due to } \\
& \text { outdated app }\end{array}$ \\
\hline Accessibility & $\begin{array}{ll} & \text { Non-conformance to } \\
& \text { WCAG standards }\end{array}$ \\
\hline
\end{tabular}

\subsection{What Measures were taken considering Covid-19 Pandemic?}

The wake of covid-19 has caused a lot of adjustment to the way people interact. In this study measures taken into consideration because of covid-19 was investigated, only one study [21] mentioned the use of zoom meeting recordings and surveys to examine the participant information while using the website because of social distancing.

\section{DISCUSSIONS}

This study presents a systematic literature review on University website usability evaluation from studies done between 2016 and 2021 based on 32 research articles. It shows research trends between these periods. Several literature reviews have been done on website usability evaluation generally, but very few studies have focused on University website usability evaluation. Result of this study showed that apart from the general objective of evaluating the general usability of University websites, some researchers had specific objectives to evaluate the accessibility of websites, determine variables that affect users of websites, investigate navigability, assess performance, propose a model for University website evaluation and compare the performance of automated tools on websites. The most used usability metric was accessibility, $47 \%$ of the articles conducted evaluation with the tool based method, while $31.2 \%$ used empirical method. The most common method of data collection was questionnaire, $87.5 \%$ used descriptive analysis while $12.5 \%$ used predictive analysis. Only one study carried out evaluation at pre-production stage while all others at completion stage. Usability problems found were related to interface design, navigation, content, and performance and accessibility issues.

It was noted that many of the universities did not meet up to the standard of usability, usability evaluation should be included at the developmental stage, it was noted that usability is also taken as user experience by some researchers, [18] used UX attributes to measure usability. Some of the studies mentioned usability values not stating the problems found, stating the problems will help other researches. It was also noted that only university staff and faculty are employed as respondent, prospective students, parents could be respondent too to have a general overview from the aspect on non-university

users. 


\section{REFERENCES}

[1] Pinho, C., Franco, M., \& Mendes, L. (2018). Web portals as tools to support information management in higher education institutions: A systematic literature review. International Journal of Information Management, 41(May 2017), 80-92. https://doi.org/10.1016/j.ijinfomgt.2018.04.002

[2] Deedam, F. B., Thomas, E., \& Taylor, O. E. (2018). Accessibility and Usability Evaluation of State-Owned Universities Website in Nigeria. International Journal of Engineering Trends and Technology, 56(1), 31-36. https://doi.org/10.14445/22315381/ijett-v56p206

[3] Muhammad, A., Siddique, A., Naveed, Q. N., Khaliq, U., Aseere, A. M., Hasan, M. A., ... Shahzad, B. (2021). Evaluating Usability of Academic Websites through a Fuzzy Analytical Hierarchical Process.

[4] Solomon, A. A., Ishaq, O. O., Muhhammad, B. A., \& Adamu, A. M. (2019). a Survey of Research Trends on University Websites' Usability Evaluation. I-Manager's Journal on Information Technology, 8(2), 11. https://doi.org/10.26634/jit.8.2.15714

[5] International Organization for Standardization. (2018). Ergonomics of human-system interaction - Part 11: Usability: Definitions and concepts (ISO 9241-11:2018). Retrieved from https://www.iso.org/standard/63500.html

[6] Ramanayaka, K. H., Chen, X., \& Shi, B. (2018). UNSCALE: A Fuzzy-based Multi-criteria Usability Evaluation Framework for Measuring and Evaluating Library Websites UNSCALE: A Fuzzy-based Multicriteria Usability Evaluation Framework for, 4602. https://doi.org/10.1080/02564602.2018.1498032

[7] Campoverde-Molina, M., Luján-Mora, S., \& Valverde, L. (2021). Accessibility of university websites worldwide: a systematic literature review. Universal Access in the Information Society. Springer Berlin Heidelberg. https://doi.org/10.1007/s10209-021-00825$\mathrm{z}$

[8] Yerlikaya, Z., \& Durdu, P. O. (2017). Usability of university websites: A systematic review. Lecture Notes in Computer Science (Including Subseries Lecture Notes in Artificial Intelligence and Lecture Notes in Bioinformatics), 10277 LNCS, 277-287. https://doi.org/10.1007/978-3-319-58706-6_22

[9] Siddaway, A. P., Wood, A. M., \& Hedges, L. V. (2019). How to Do a Systematic Review: A Best Practice Guide for Conducting and Reporting Narrative Reviews, Meta-Analyses, and Meta-Syntheses. Annual Review of Psychology, 70(July), 747-770. https://doi.org/10.1146/annurev-psych-010418-102803
[10] Moher, D., Liberati, A., Tetzlaff, J., Altman, D. G., \& Grp, P. (2009). Preferred Reporting Items for Systematic Reviews and Meta-Analyses: The PRISMA Statement (Reprinted from Annals of Internal Medicine). Physical Therapy, 89(9), 873-880. https://doi.org/10.1371/journal.pmed.1000097

[11] Acosta-Vargas, P., Acosta, T., \& Lujan-Mora, S. (2018). Challenges to assess accessibility in higher education websites: A comparative study of Latin america universities. IEEE Access, 6, 36500-36508. https://doi.org/10.1109/ACCESS.2018.2848978

[12] Abuqaddom, I., Alazzam, H., Hudaib, A., \& Alzaghoul, F. (2019). A measurable website usability model: Case Study University of Jordan. 2019 10th International Conference on Information and Communication Systems (ICICS), 83-87.

[13] Alfayez, Z. H., Altawriy, H. M., \& Science, C. (2020). Usability Evaluation of Educational Websites: A case Study of University of Basrah Website.

[14] Akgul, Y. (2017). The most violated WCAG 1.0 guidelines by the developers of university websites in Turkey. Iberian Conference on Information Systems and Technologies, CISTI. https://doi.org/10.23919/CISTI.2017.7976007

[15] Demir, F. (2018). The Usability Of King Khalid University Website: Assessing Effectiveness, Efficiency, And Satisfaction. www.ijahss.com International Journal of Arts Humanities and Social Sciences (Vol. 3). Retrieved from www.ijahss.com

[16] Baroudi, M. (2020). Evaluation of Accessibility and Usability of Higher Education Institutions 'Websites of Jordan, 125-130. https://doi.org/10.1109/ICICS49469.2020.239565

[17] Harrati, N., Bouchrika, I., Tari, A., \& Ladjailia, A. (2016). Computers in Human Behavior Exploring user satisfaction for e-learning systems via usage-based metrics and system usability scale analysis. Computers in Human Behavior, 61, 463-471. https://doi.org/10.1016/j.chb.2016.03.051

[18] Pilarcikova, K., Rusnak, P., Rabcan, J., \& Kostolny, J. (2019). User Experience in the Development of the Education System. 2019 17th International Conference on Emerging ELearning Technologies and Applications (ICETA), 626-632.

[19] Firdaus, B. (2019). Analysis of the Effect of Quality Mulawarman University Language Center websites on User Satisfaction Using the Webqual 4 . 0 Method, 126132. 
International Journal of Computer Applications Technology and Research

Volume 11-Issue 02, 22-28, 2022, ISSN:-2319-8656

DOI:10.7753/IJCATR1102.1003

[20] Najadat, H., \& Al-badarneh, A. (2017). Evaluating Jordanian Universities Websites Based on Data Envelopment Analysis, 159-164.

[21] Lonergan, V., Lonergan, C., \& Usability, J. (2020). Usability Evaluation of the Trulaske College of Business Website. 